\title{
Verbal fluency, naming and verbal comprehension: three aspects of language as predictors of cognitive impairment
}

\author{
Ana Maseda, Leire Lodeiro-Fernández, Laura Lorenzo-López, Laura Núñez-Naveira, \\ Aránzazu Balo and Jose C. Millán-Calenti \\ Department of Medicine, Gerontology Research Group, Faculty of Health Sciences, University of A Coruña, A Coruña, Spain
}

\begin{abstract}
Objectives: To establish the possible relationship among three components of language (verbal fluency, naming and comprehension) and cognitive impairment as well as to determine the usefulness of language assessment tests to predict or monitor the development of cognitive impairment.

Method: A comparative, descriptive and cross-sectional study was performed on 82 subjects $>=65$ years of age who were cognitively assessed with the Mini Mental State Examination and were divided into two groups: Group A comprised of subjects classified as levels 1, 2 and 3 on the Reisberg's Global Deterioration Scale (GDS) and group B comprised of subjects at levels 4 and 5 of the GDS. Language skills were assessed by the Verbal Fluency Test, Boston Naming Test and Token Test.

Results: An inverse relationship between performance on language tests and cognitive impairment level was observed with a more pronounced effect observed on fluency and comprehension tests.

Conclusion: Language assessments, especially fluency and comprehension, were good indicators of cognitive impairment. The use of these assessments as predictors of the degree of cognitive impairment is discussed in-depth.
\end{abstract}

Keywords: language test; cognitive disorders; language disorders; comprehension; cognitive test

\section{Introduction}

Language is the main mode of communication and an essential means of human socialization. Language skills are cognitive abilities that change with aging and involve the integration of multiple processes and cognitive areas, which may be related to cognitive impairment conditions (Juncos-Rabadán \& Pereiro, 1998; López Pérez-Díaz, Dolores Calero, \& Navarro-González, 2013; Millán Calenti, Lodeiro Fernández, \& Crespo López, 2006).

Some language functions do not change in old age, whereas others appear to decline with age. The main agerelated physiological deficits are related to phonological or orthographic retrieval in the comprehension and verbal production processes related to semantic memory access. This is the case in fluency tasks (Bayles \& Boone, 1982; Taylor \& Burke, 2002) in which implementation requires the use of complex neural networks related to semantic memory, working memory or executive functions (Amunts et al., 2004). Verbal fluency performance requires two underlying cognitive processes: 'clustering' (i.e., the ability to produce words within semantic or phonemic subcategories) and 'switching' (the ability to shift between clusters). Both are dissociable components, but switching appears to be more related to frontal lobe functions (Troyer, Moscovith, \& Winocur, 1997).

Performance on cognitive tests has proven to be useful as an early marker for the detection of several diseases and to classify advanced stages of dementia such as Alzheimer's disease (Gomez \& White, 2006; McDowd et al., 2011; Pascual-Millán et al., 1990). The sensitivity and specificity of these tests are higher than those of some commonly used and intensive neuropsychological tests (Heun, Papassotiropoulos, \& Jennsen, 1998). Verbal fluency scores have demonstrated sensitivity to cognitive impairment across mild to moderate Alzheimer's disease, and have been shown to differentiate probable Alzheimer's disease from subcortical ischemic vascular dementia (Consentino, Scarmeas, Albert, \& Stern, 2006; Tierney et al., 2001).

Over the last decade, several studies (Henry \& Crawford, 2004; Monsch et al., 1992) have suggested that semantic fluency is more often affected in patients with dementia of the Alzheimer type or mild cognitive impairment (MCI), while amnestic MCI patients did not demonstrate changes in phonemic fluency when compared to healthy controls (Murphy, Rich, \& Troyer, 2006). It has also been observed that Alzheimer's disease results in a dual impairment of process and content of conceptual knowledge in the semantic memory (Reilly, Peelle, Antonucci, \& Grossman, 2011). Semantic fluency has also been associated with other variables, such as age, sex and educational level (Carnero, Lendínez, Maestre, \& Zunzunegui, 1999), as well as with the test duration (Fernández-Turrado et al., 2007). 
Vocabulary scores are not age insensitive, demonstrating a substantial and positive increase with advancing age. Although naming or lexical access scores are higher in older adults compared to younger adults (Verhaeghen, 2003), some difficulties can be observed in spontaneous speech or objects and people naming (Juncos-Rabadán, Facal, Soledad Rodríguez, \& Pereiro, 2010; Juncos-Rabadán \& Pereiro, 1998). This effect is not a consequence of a problem with knowledge but rather that of word finding. A clear example of this situation is the tip-of-the-tongue phenomenon, which is known to occur more frequently in elderly (Burda, 2011).

Naming performance shows a significant decline over time and this effect has been shown to be greater for the oldest subjects (Au et al., 1995; Pineda et al, 1998). In addition, an inverse effect of education on naming performance has been observed (Saxton et al., 2000).

Verbal comprehension is usually better preserved than the productive aspects of language, such as fluency and naming, but some difficulties are encountered when the material is complex (Juncos-Rabadán \& Pereiro, 1998), mainly due to changes in working memory. Comprehension can also be affected by alterations in the information input process, which are closely related to hearing. However, these aspects do not fully explain the comprehensive difficulties in advanced age (Salthouse, 1991).

Thus, language function undergoes age-related changes that vary in severity and etiology depending on the aspect being studied. Lexical and semantic organization does not suffer major changes, but access to this knowledge does, which manifests as difficulty in naming tasks and verbal fluency (Burke \& Shafto, 2004; Verhaeghen, 2003). The verbal comprehension difficulties are the consequences of other alterations, either cognitive (attention or working memory) or hearing alterations (Juncos-Rabadán \& Pereiro, 1998; Kemper, 1992; Salthouse, 1991).

Dementia usually implies a progressive deterioration in cognitive, communicative and linguistic abilities, which is more severe than that observed in normal aging. Nevertheless, at the beginning of the dementia process, these alterations are not different from those observed with physiological aging, which creates difficulty in clearly differentiating between normal aging, mild impairment and dementia at an early stage (Perkins, Whitworth, \& Lesser, 1997). In general, when assessing these three aspects of language (fluency, naming and comprehension), there are scarce data with regard to naming and comprehension areas, which may be due to use of different versions of tests. In addition, there are few language assessment tests specifically designed for older people. Some authors have tried to develop screening procedures based on language assessments (Bayles \& Boone, 1982; Bryan et al., 2001) to discriminate between the early stages of dementia, but these results may not be applicable for diagnosing different degrees of cognitive impairment.

Based on the above, the main objective of this work was to establish the possible relationship among three components of language (verbal fluency, naming and comprehension) and cognitive impairment as well as to determine the usefulness of language assessment tests to predict or monitor the development of cognitive impairment.

\section{Design and methods}

\section{Participants}

A comparative, descriptive and cross-sectional study was carried out on a sample of subjects $>=65$ years of age who attended a center specializing in the care of dependent adults in A Coruña, Spain. The study was approved by the Ethics Committee of the University of A Coruña, and was in conformity with the principles embodied in the Declaration of Helsinki. All subjects were informed in advance about the study and gave their consent to participate in the study, either directly or through their legal representatives.

Given that our main objective was to determine the relationship among language components and cognitive impairment, we divided the total sample into two subgroups according to Reisberg's Global Deterioration Scale (GDS) (Reisberg, Ferris, \& de Leon, 1988). This scale, which has been proven to be reliable and valid for staging dementia in different settings, describes seven stages of cognitive function from one (no subjective complaints of memory deficit) to seven (very severe cognitive impairment). Thus, using this scoring system, we established a normal predementia group (Group A [GA], GDS scores between 1 and 3;1 = no cognitive decline, $2=$ very mild cognitive decline, $3=$ mild cognitive decline) and a moderate-severe dementia group (Group B [GB], GDS scores 4 and 5; $4=$ moderate cognitive decline, 5 = moderately severe cognitive decline).

The subjects with characteristics that were incompatible with the administration of the selected assessment tests were excluded from the study, specifically, those with non-dementia cognitive alterations, such as stroke, altered visual perception for images and colors; with limited motor ability of the upper extremities; or in groups 6 and 7 of the GDS. 


\section{Variables and instruments}

The GDS (Reisberg et al., 1988) and the Mini-Mental State Examination (MMSE) (Folstein, Folstein, $\&$ McHugh, 1975) were used to assess cognitive status and were administered by a qualified clinical psychologist. Regarding MMSE, a validated Spanish version that provided an adjustment of the scores according to age and educational level (Blesa et al., 2001) was administered. The MMSE is one of the simplest and most universally used tests for screening and quantifying cognitive impairment and includes items that assess five cognitive domains. The total cognitive score corresponds to the highest cognitive status, with a cut-off score of 24/25 (non-demented = above 24).

The three specific instruments selected to assess language function were: the Verbal Fluency Test (VFT) (Lezak, Howieson, Loring, Hannay, \& Fisher, 2004; Spreen \& Strauss, 1998), to specifically assess fluency; the Boston Naming Test (BNT) (Kaplan, Goodglass, \& Weintraub, 2005), to assess naming; and the Token Test (TT) (Derenzi \& Vignolo, 1962), to assess comprehension.

The VFT is widely used in neuropsychological assessment due to its speed of administration, simplicity and sensitivity, and it has been considered a screening test on its own for cognitive impairment and dementia (Caramelli, Carthery-Goulart, Porto, Charchat-Fichman, \& Nitrini, 2007; Carnero-Pardo \& Lendínez-González, 1999; Cummings, 2004). The test allows 60 seconds for an individual to verbally list as many things as possible in the 'animal category' and registers the number of items in each of the four time segments that are composed of the one-minute period. The final score refers to the exact number of correct and non-repeated evocations listed by the subject. The cut-off for impairment is established as $<10$ points (Carnero-Pardo \& Lendínez-González, 1999). Two other aspects are also recorded with this test: the repetitions or perseverations given by the subjects during the evocation task and the occurrence of at least one change in subcategory or 'switching'.

Regarding the BNT, which is used to assess the individual's ability to name two-dimensional line drawings of objects, we used a short form that consisted of 15 items or objects. Subjects were allowed approximately 20 seconds to name each drawing. If the correct word was not produced in that time, a phonemic cue was given and an additional 20 seconds was allowed for a response. Correct responses for the spontaneously correct and stimuluscued conditions were scored as the same (Kaplan et al., 2005).

Regarding the TT, the original version was administered, which includes 62 instructions that are divided into five parts: Parts I to IV contain 10 verbal commands each, and Part V consists of 22 instructions. Each part presents a successive increase in the level of difficulty, but within each part, the level of difficulty is comparable. For each instruction that is correctly performed, the subject receives one point with a maximum obtainable score of 62 points.

\section{Procedure}

Qualified staff in the gerontology field assessed participants during two sessions to avoid fatigue: a speech therapist for issues related to language function and a psychologist for those assessments of cognitive status.

\section{Statistical analyses}

All the recorded variables were analyzed in a descriptive way. Categorical variables were expressed as frequency tables, while the quantitative variables were displayed according to measures of central tendency (the mean) and dispersion (the standard deviation). Student's $t$ statistic was used for the comparison of the means in each of the subgroups assuming equal variances. To determine the relationship among variables, a multiple linear regression model was used for the calculation of Spearman's rank correlation coefficient. The association between variables was analyzed by Pearson's correlation coefficient. Statistical analyses were conducted using SPSS v. 16.0.1 (SPSS Inc., 2007).

\section{Results}

\section{Sample characteristics}

The sample consisted of 82 subjects, with 40 (48.8\%) meeting the criteria defined for the GA (normal predementia group) and $42(51.2 \%)$ for the GB (moderate-severe dementia group). One subject in the GA (2.5\%) was classified as being without cognitive impairment (GDS 1), 16 (40\%) had very MCI (GDS 2) and the remaining $23(57.5 \%)$ suffered from MCI (GDS 3). In the GB, 24 subjects (57.1\%) exhibited moderate cognitive impairment (GDS 4) and 18 (42.9\%) exhibited moderate to severe impairment (GDS $5)$. 
The sociodemographic characteristics of the sample (age, sex and level of education) are shown in Table 1 as a function of the group (GA and GB). There were no statistically significant differences between the both groups in the mean age $(p=0.822)$ or education level $(p=0.186)$.

\section{Verbal fluency, naming and comprehension tests}

The participant's performance on the administered language tests is shown in Table 2 for both groups.

Regarding the VFT, the GA obtained a greater number of evoked words compared to the GB for each period subset with a greater observed difference between groups over the first 15 seconds $(4.3 \pm 1.5$ words vs. $1.8 \pm 1.4$ words). The final scores were significantly different between groups (GA: $9.1 \pm 3.9$ words; GB: $3.5 \pm 2.3$ words). Additionally, in both groups, performance decreased progressively throughout the one-minute test duration, with performance being significantly higher during the first 15 seconds. As shown in Table 2, significant differences $(p<0.005)$ were observed for all inter-group comparisons, except for the variable repeats/perseverations, where no significant differences were found between groups.

Regarding the BNT, the GA showed more spontaneous responses and the greatest resolution with semantic, phonemic and multiple-choice cues, and they needed fewer cues compared to the GB group. Student's t-test revealed significant differences $(\mathrm{p}<0.05$ or $\mathrm{p}<0.005)$ between groups in all of the measured BNT variables, with the exception of the number of correct responses after a phonemic cue.

Table 1. Sociodemographic characteristics of the study population.

\begin{tabular}{lccc}
\hline & $\begin{array}{c}\text { GA } \\
(\mathrm{n}=40)\end{array}$ & $\begin{array}{c}\text { GB } \\
(\mathrm{n}=42)\end{array}$ & $\begin{array}{c}\text { Total } \\
(\mathrm{n}=82)\end{array}$ \\
\hline Age & $83.5 \pm 6.1$ & $83.2 \pm 6.4$ & $83.4 \pm 6.2$ \\
Age range & $65-94$ & $66-94$ & $65-94$ \\
Gender (\%) & 75 & 78.6 & 76.8 \\
$\quad$ Female & 25 & 21.4 & 23.2 \\
$\quad$ Male & & & \\
Educational level (\%) & 5.0 & 2.4 & 3.7 \\
$\quad$ Uneducated & 22.5 & 33.3 & 28.0 \\
Able to read and write & 50.0 & 52.4 & 51.2 \\
Primary schooling & 7.5 & 4.8 & 6.1 \\
Secondary schooling & 15.0 & 7.1 & 11.0 \\
$\quad$ University studies & & & \\
\hline
\end{tabular}

Note: Group A (GA), group B (GB).

Finally, the TT results overall suggested the presence of a comprehensive disorder, especially in the GB. The GA mean score $(46.3 \pm 9.2)$ was slightly below the established test cut-off point (49 points), while the GB mean score was significantly lower $(29.9 \pm 12.8)$. The average number of errors significantly increased as the test progressed, according to the sentences' complexity. The GB showed inferior performance on all test parts compared to the GA. Student's t-test showed significant inter-group differences $(\mathrm{p}<0.005)$ in all of the measured TT variables, indicating that the number of errors varied depending on the subject's cognitive status.

\section{Relationship between language tests and cognitive impairment}

Furthermore, to increase the sensitivity of the inter-group differences, the score for each language test at every GDS level was evaluated, with GDS 1, 2 and 3 for GA and GDS 4 and 5 for GB (see Table 3). An inverse relationship was observed between the results obtained and the level of GDS, with the subjects who belonged to less impaired GDS groups demonstrating superior results. In the same vein, the subjects who belonged to GDS 5 yielded the poorest results, a finding that implies that as GDS level increases, performance in language tests significantly decreases. 


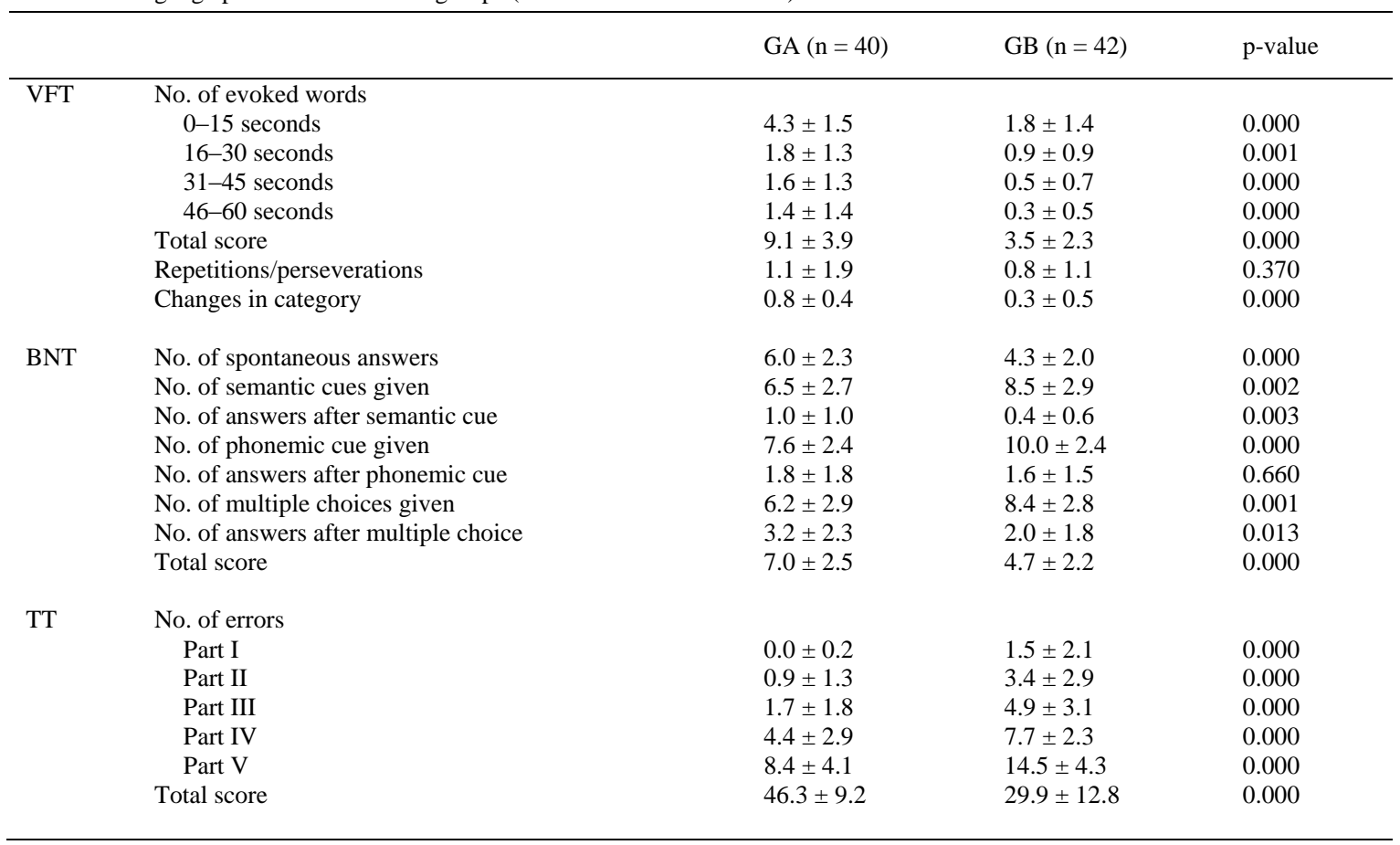

Note: Verbal Fluency Test (VFT), Boston Naming Test (BNT), Token Test (TT), group A (GA), group B (GB).

Next, to objectify the presence or absence of a linear correlation between variables related to language (VFT, BNT and TT) and cognitive status, Pearson's correlation coefficient (r) was computed. Significant correlations $(p<0.005)$ were found that exceeded the value of the standard error multiplied by student's $\mathrm{t}$-test, revealing a linear correlation between each of the language tests and the score on the MMSE. In addition, the coefficient of determination (r2) (see Table 4) was calculated to determine the MMSE score effect in the three language assessment tests.

To ascertain the predictive value of the sociodemographic variables (age, sex and educational level) along with those of language on cognitive status, a multiple linear regression model was formulated (see Table 5, phase A). In this model, with the six variables grouped, age, sex, educational level and naming (as assessed by the BNT) had no predictive value on cognitive status. However, fluency (VFT) and comprehension (TT) were predictive variables for cognitive decline. Sociodemographic variables were eliminated in the subsequent multiple linear regression model (see Table 5, phase B), which included only the language tests. The results revealed that only VFT and comprehension tests had predictive value for cognitive impairment $(\mathrm{p}<0.005$ ), indicating that the adjusted model determined much of the response variability.

Table 3. The results are expressed as the mean and standard deviation scores for the VFT, BNT and TT according to GDS degree.

\begin{tabular}{lccc}
\hline & VFT & BNT & TT \\
\hline GDS 1 $(\mathrm{n}=1)$ & 15 & 11 & 53 \\
GDS 2 $(\mathrm{n}=16)$ & $10.9 \pm 4.0$ & $8.0 \pm 2.6$ & $50.1 \pm 7.3$ \\
GDS 3 $(\mathrm{n}=23)$ & $7.7 \pm 3.3$ & $6.2 \pm 2.1$ & $43.3 \pm 9.5$ \\
GDS 4 $(\mathrm{n}=24)$ & $4.1 \pm 1.9$ & $5.2 \pm 2.1$ & $33.9 \pm 11.2$ \\
GDS 5 $(\mathrm{n}=18)$ & $2.6 \pm 2.6$ & $4.1 \pm 2.3$ & $24.5 \pm 13.1$ \\
& & & \\
\hline
\end{tabular}

Note: Verbal Fluency Test (VFT), Boston Naming Test (BNT), Token Test (TT), Global Deterioration Scale (GDS).
Table 4. Pearson's correlation coefficient ( $\mathrm{r}$ ) and coefficient of determination $\left(\mathrm{r}^{2}\right)$ between the variables VFT, BNT and TT and the MMSE scores.

\begin{tabular}{lccc}
\hline & $\mathrm{r}$ & $\mathrm{r}^{2}$ & $\mathrm{p}$-value \\
\hline & & & \\
VFT & 0.722 & 0.49 & 0.000 \\
BNT & 0.565 & 0.32 & 0.000 \\
TT & 0.707 & 0.47 & 0.000 \\
& & & \\
\hline
\end{tabular}

Note: Verbal Fluency Test (VFT), Boston Naming Test (BNT), Token Test (TT), Mini-Mental State Examination (MMSE). 
Afterwards, a simple linear regression analysis was performed to determine the variability of the response, as explained by each of the independent variables (see Table 5, Phase C). In this case, the response variability increased substantially and independently for verbal fluency $(0.722)$ and for comprehension (0.707). In addition, the BNT independently explained 56\% of the response variability.

Finally, to analyze the predictive value of the sociodemographic variables (age, sex and educational level) on the language test performance, a multiple linear regression model was formulated (see Table 6). In this model, only educational level demonstrated a predictive value by the naming test (BNT).

Table 5. Linear regression analysis to determine the predictive value of different variables on cognitive decline.

\begin{tabular}{|c|c|c|c|}
\hline & & B coefficient & $\mathrm{p}$-value \\
\hline \multirow[t]{6}{*}{ Phase A } & Age & 0.060 & 0.369 \\
\hline & Sex & -0.067 & 0.343 \\
\hline & Educational level & -0.099 & 0.173 \\
\hline & VFT & 0.451 & 0.000 \\
\hline & BNT & 0.070 & 0.460 \\
\hline & $\mathrm{TT}$ & 0.437 & 0.000 \\
\hline \multirow[t]{3}{*}{ Phase B } & VFT & 0.464 & 0.000 \\
\hline & BNT & 0.045 & 0.612 \\
\hline & $\mathrm{TT}$ & 0.427 & 0.000 \\
\hline \multirow[t]{3}{*}{ Phase C } & VFT & 0.722 & 0.000 \\
\hline & BNT & 0.565 & 0.000 \\
\hline & $\mathrm{TT}$ & 0.707 & 0.000 \\
\hline
\end{tabular}

Note: Verbal Fluency Test (VFT), Boston Naming Test (BNT), Token Test (TT). Phase A:

Multiple linear regression analysis among age, sex, educational level and language tests (VFT, BNT and TT) on cognitive decline. Phase B: Multiple linear regression analysis of language tests on cognitive decline. Phase C: Simple linear regression analysis of language tests on cognitive decline.

\section{Discussion}

The semantic components of language are more vulnerable to aging than other focal aspects, such as syntax and phonology (Shadden, 1997). For this reason, verbal fluency and naming confrontation tasks are particularly affected in Alzheimer's disease (Arroyo-Anlló, Lorber, Rigaleau, \& Gil, 2012; Weingartner, Kawas, Rawlings, \& Shapiro, 1993). It has been demonstrated that semantic impairment in patients with mild Alzheimer's disease begins with a loss of conceptual associations, and that the semantic relations acquired earlier in childhood are better preserved than those acquired in later developmental stages (Di Giacomo et al., 2012). The MCI is also characterized by fluency and naming confrontation disorders and, to a lesser extent, disorders of sentence comprehension, although the relationships of these disorders with other cognitive processes, psychophysiological and neurological correlates are complex and not well understood (Juncos-Rabadán, Pereiro, Facal, \& Rodríguez, 2010).

\section{Verbal fluency and cognitive impairment}

Our results are consistent with previous studies (Monsch et al., 1992; Pascual-Millán et al., 1990) in which the alteration of semantic verbal fluency has been shown to be strongly associated with dementia and Alzheimer's disease. Gomez and White (2006) also suggest that semantic fluency tests are sensitive in the detection of Alzheimer's disease.

Similar to Horton and Reynolds (2007), our results showed that the loss of verbal fluency was also present in the MCI participants. Nevertheless, whether the fluency loss occurred in all of the subtypes of MCI or only in the amnestic one as noted by Murphy et al. (2006), could not be determined. Loss of verbal fluency is influenced by the specific semantic category in addition to an MCI subtype effect (Emery, 2000). In our study, we assumed a cultural heterogeneity in the sample and selected the category of 'animals' because we considered it to be the most common and neutral, even though it is not as discriminatory for the MCI subtype.

Our results revealed that inter-group differences in verbal fluency were more noticeable during the first 15 seconds. In both groups, the majority of evocation was performed in the first half minute and then decreased, which confirmed that the level of effort is lower during the first seconds of execution (Fernández-Turrado et al., 2007). 
Table 6. Multiple linear regression model to examine the predictive value of sociodemographic variables on language performance (VFT, BNT and TT).

\begin{tabular}{|c|c|c|c|c|c|c|}
\hline & \multicolumn{2}{|c|}{ VFT } & \multicolumn{2}{|c|}{ BNT } & \multicolumn{2}{|c|}{$\mathrm{TT}$} \\
\hline & B coefficient & p-value & B coefficient & $\mathrm{p}$-value & ß coefficient & p-value \\
\hline Age & 0.017 & 0.884 & -0.031 & 0.770 & -0.010 & 0.932 \\
\hline Sex & -0.025 & 0.835 & -0.137 & 0.217 & 0.024 & 0.834 \\
\hline
\end{tabular}

Note: Verbal Fluency Test (VFT), Boston Naming Test (BNT), Token Test (TT).

The GB (moderate-severe dementia group) demonstrated difficulty in generating words within the same subcategory ('clustering') and, more notably, in switching from one subcategory to another ('switching'), as it is more common for individuals to remain within the subcategory, e.g., 'domestic animals' (Troyer et al., 1997). This result is consistent with a recent publication (Haugrud, Crossley, \& Vrbancic, 2011) that reported that the analysis of clustering and switching strategies could distinctly classify those patients with Alzheimer's disease. In line with our results, they observed less 'switching' in the cognitive impairment group, thereby demonstrating the validity of this test to differentiate between healthy individuals and those with cognitive impairment. Another study also found that the number of switchings decreased with age, but the differences in clustering measures were not as obvious (Lanting, Haugrud, \& Crossley, 2009), which further supports the validity of our findings.

However, with regard to the interpretation of these findings, a potential limitation may be that the handedness of the subjects was not taken into account. Sontam, Christman, \& Jasper (2009) observed that ambidextrous individuals had a higher switching frequency than individuals who preferentially used one of their two hands. These findings have implications for any research that uses these fluency tests to determine patients' cognitive status. Regardless, given that $85 \%$ of people are right-handed (Uomini, 2009), we propose that the results of this study reflect true differences in the switching function of the elderly.

Similar to Monsch et al. (1992), our study proved to be objective and unambiguous regarding effects on the semantic system in the GB that occurred from the beginning of the cognitive decline and, as indicated by Murphy et al. (2006), manifested a progressive decline from physiological aging to dementia.

On the contrary, age and educational level demonstrated no association with cognitive decline. These findings are consistent with those of a recent longitudinal study (Zahodne et al., 2011), which suggested that educational level had no influence on cognitive decline, thereby supporting the hypothesis of passive cognitive reserve during aging.

\section{Naming and cognitive impairment}

With regard to naming, the GA scores did not significantly differ from established scores in physiological aging, wherein it has been noted that naming by visual confrontation is diminished and more errors occur when speed is required or when a less frequently used name or a proper name is used (Shadden, 1997).

According to Kertesz (1994), naming by visual confrontation may be affected by age, level of education, familiarity with objects, frequency of use, length, semantic category and even the grammatical classification of the word. Authors posit that the frequency of use and object familiarity are the main factors that affect naming because the evocation difficulties increased as the test progressed, that is, as the terms became less familiar and were less frequently used. Moreover, according to these studies, our results showed that the educational level is a predictive factor for BNT performance. Nevertheless, with respect to the analysis of the VFT outcomes, we observed that neither age, nor sex or the educational level were predictive variables for fluency. This result was consistent with a prior study (Fritsch et al., 2007) revealing that the educational level has direct effects on global cognitive functioning, but not on verbal fluency.

Our results also revealed that the difficulties in lexical access were more evident in the moderate to severe dementia group, in which semantic and multiple-choice cues were less useful. With regard to phonological cues, no significant inter-group differences were observed. 
If we propose that the need for semantic cues is due to a subject's visual perception problem, it may be concluded that perceptual difficulty was hardly prevalent in both groups. Nevertheless, this perceptual difficulty was more characteristic in the GA.

Semantic cues were also offered when the response demonstrated low specificity, e.g., 'plant' instead of 'cactus'. In these circumstances, once a perceptual problem was ruled out, the lack of benefit from phonological and semantic cues indicated proper access to the semantic category but not to its different components, suggesting an impairment of linguistic structures or the lack of vocabulary (JuncosRabad_an, Facal, et al., 2010).

In subjects with advanced cognitive impairment, the changes appeared to extend beyond the perceptual level and that of vocabulary. A perceptual deficit is not likely because correct answers were given for images of common objects and more difficulties were observed with the subsequent less frequently used words. Many subjects were able to gain access to the semantic category but not to the exact item in that category (e.g., plant instead of cactus, or rat instead of beaver). Other individuals failed to access the appropriate semantic representation, possibly due to a poor vocabulary level that did not facilitate semantic activation (Juncos-Rabad_an, Facal, et al., 2010).

Previous studies have reported that poor BNT performance of Alzheimer's patients cannot be completely explained by semantic breakdown, and that naming difficulties in these patients are explained by a combination of loss of semantic knowledge, impaired lexical access and higher taxing of cognitive resources for finer grained discrimination between basic level lexical-semantic fields (Balthazar, Cendes, \& Damasceno, 2008).

According to previous studies (Aranciva et al., 2012; Au et al., 1995; Bayles, 1985; FernándezBlázquez et al., 2012; Toumbaugh \& Hubbley, 1997), the BNT was clearly associated with the education level and thus, predictably, with the lexical knowledge in our study. Furthermore, it should not be overlooked that deterioration in semantic aspects is evident in Alzheimer's disease (Emery, 2000; Reilly et al., 2011). Although the age effect in elderly persons $>80$ years of age has been previously demonstrated (Aranciva et al., 2012; Welch, Doineau, Johnson, \& King, 1996), we did not observe that relationship in our study.

\section{Comprehension and cognitive impairment}

Emery (2000) reported that the language decline observed in Alzheimer's disease appears to be hierarchical among its different levels (phonology, morphology, syntax and semantics), and occurs in reverse fashion to its acquisition, being semantic processing more complicated in sentences than in words. Our study demonstrated more difficulties among participants in the evocation of words than in the comprehension of simple sentences. According to this study, comprehension is better preserved in the expressive aspects of naming and verbal fluency (Juncos-Rabadán \& Pereiro, 1998).

Comprehension decline notably occurs during the eighth decade of life and it appears to be associated with working memory (Au \& Bowles, 1991; Shadden, 1997). Higher levels of cognitive and perceptual stress produce a greater likelihood of errors in speech comprehension (Pichora-Fuller, 2003). Our data confirmed that the errors increased as the test progressed and also with increased syntactic complexity and length of sentences, thereby confirming differences observed in subjects with greater cognitive impairment. As regards age and level of education as influential factors in the TT (Aranciva et al., 2012; Snitz et al., 2009), no significant differences were noted.

Therefore, persons with dementia perform better with regard to verbal comprehension when the syntactic complexity of sentences is diminished and when these syntactic structures are acquired earlier in life (Chomsky, 1979; Emery, 2000). No decline in verbal comprehension has been previously observed in healthy subjects (Moreira et al., 2011).

Finally, individuals suffering from Alzheimer's disease develop pathological brain alterations that commence before the appearance of clinical symptoms (Braak \& Braak, 1991), being the degree or the localization of damage correlated with the severity of dementia (Snowdon, 1997). Cognitive deficits may also be obvious before the onset of dementia. Thus, there is growing interest in the study of MCI because it is considered to be a transitional phase between normal cognitive function and clinically probable Alzheimer's disease (Winblad et al., 2004). Language deficit is one of the criteria used in the diagnosis of MCI. Early treatment of this condition is critical prior to the onset of extensive brain damage (Cummings, Doody, \& Clark, 2007) and, therefore, progress in optimization or selective screening techniques in the population can be expected to have a substantial positive impact on treatment selection. Our results demonstrated that fluency, naming and verbal comprehension are associated with the degree of cognitive impairment in the sample population analyzed. Thus, stimulation of these three aspects of language through a customized program may generate improvement in the cognitive status. 


\section{Conclusion}

We have described different features of language processing with regard to cognitive status. An inverse relationship between performance on language tests and the level of cognitive impairment was observed, with greater effects on fluency and comprehension tests. Therefore, language tests, particularly those in fluency and comprehension, may be considered as suitable indicators of cognitive impairment. In turn, these findings carry predictive value regarding the degree of impairment severity and will permit the selection of appropriate cognitive stimulation programs to adequately treat these patients.

\section{Acknowledgements}

The authors wish to sincerely thank the Gerontological Complex 'La Milagrosa' for providing access to their elderly residents.

\section{References}

Amunts, K., Weiss, P.H., Mohlberg, H., Pieperhoff, P., Eickhoff, S., Gurd, J.M., . . Zilles, K. (2004). Analysis of neural mechanisms underlying verbal fluency in cytoarchitectonically defined stereotaxic space: The roles of Brodmann areas 44 and 45. Neuroimage, 22, 42-56. doi: 10.1016/j.neuroimage.2003.12.031

Aranciva, F., Casals-Coll, M., Sánchez-Benavides, G., Quintana, M., Manero, R.M., Rognoni, T., . . . PeñaCasanova, J. (2012). Spanish normative studies in a young adult population (NEURONORMA young adults project): Norms for the Boston naming test and the token test. Neurologia, 27, 394-399. doi: 10.1016/j.nrl.2011.12.016

Arroyo-Anlló, E.M., Lorber, M., Rigaleau, F., \& Gil, R. (2012). Verbal fluency in Alzheimer's diseases and aphasia. Dementia, 11, 5-18. doi: 10.1177/1471301211416609

Au, R., \& Bowles, N. (1991). Memory influences on language in normal aging. In D. Ripich (Ed.), Handbook of geriatric communication disorders (pp. 293-305). Austin, TX: Pro-Ed.

Au, R., Joung, P., Nicholas, M., Obler, L.K., Kass, R., \& Albert, M.L. (1995). Naming ability across the adult life span. Aging \& Cognition, 2, 300-311. doi: 10.1080/13825589508256605

Balthazar, M.L., Cendes, F., \& Damasceno, B.P. (2008). Semantic error patterns on the Boston naming test in normal aging, amnestic mild cognitive impairment, and mild Alzheimer's disease: Is there semantic disruption? Neuropsychology, 22, 703-709. doi: 10.1037/a0012919

Bayles, K.A. (1985). Effects on dementing illness on communicative function. San Diego, CA: International Neuropsychological Society.

Bayles, K.A., \& Boone, D.R. (1982). The potential of language tasks for identifying senile dementia. Journal of Speech and Hearing Disorders, 47, 210-217. Retrieved from: http://jshd.asha.org/cgi/reprint/47/2/210

Blesa, R., Pujol, M., Aguilar, M., Santacruz, P., Bertrán-Serra, I., Hernández, G., . . . NORMACODEM Group. (2001). Clinical validity of the mini-mental state for spanish speaking communities. Neuropsychologia, 39, 11501157. doi:10.1016/S0028-3932(01)00055-0

Braak, H., \& Braak, E. (1991). Neuropathological stageing of Alzheimer-related changes. Acta Neuropathologica, 82, 239-259. doi: 10.1007/BF00308809

Bryan, K., Binder, J., Dann, C., Funnell, E., Ramsey, V., \& Stevens, S. (2001). Development of a screening instrument for language in older people (Barnes language assessment). Aging \& Mental Health, 5, 371-378. doi: $10.1080 / 13607860120080332$

Burda, A. (2011). Verbal expression. In A. Burda (Ed.), Communication and swallowing changes in healthy aging adults (pp. 75-92). Sudbury, MA: Jones \& Bartlett.

Burke, D., \& Shafto, M.A. (2004). Aging and language production. Current Directions in Psychological Science, 31, 21-24. doi: 10.1111/j.0963-7214.2004.01301006.x

Caramelli, P., Carthery-Goulart, M.T., Porto, C.S., Charchat-Fichman, H., \& Nitrini R. (2007). Category fluency as a screening test for Alzheimer disease in illiterate and literate patients. Alzheimer Disease \& Associated Disorders, 21, 65-67. doi: 10.1097/WAD.0b013e31802f244f

Carnero, C., Lendínez, A., Maestre, J., \& Zunzunegui, M.V. (1999). Fluencia verbal semántica en pacientes neurológicos sin demencia y bajo nivel educativo [Semantic verbal fluency in neurological patients without dementia with a low educational level]. Revista de Neurologia, 28, 858-862. Retrieved from: http://www.revneurol.com/sec/resumen.php?id=98489

Carnero-Pardo, C., \& Lendínez-González, A. (1999). Utilidad del test de fluencia verbal semántica en el diagnóstico de demencia [The utility of the semantic verbal fluency test in diagnosis of dementia]. Revista de Neurologia, 29, 709-714. Retrieved from: http://www.revneurol.com/sec/resumen.php?id=99233

Chomsky, C. (1979). The acquisition of syntax in children from 5 to 10. Cambridge, MA: MIT Press.

Consentino, S., Scarmeas, N., Albert, S.M., \& Stern, Y. (2006). Verbal fluency predicts mortality in Alzheimer's Disease. Cognitive and Behavioral Neurology, 19, 123-129. doi:10.1097/01.wnn.0000213912.87642.3d

Cummings, J.L. (2004). The one-minute mental status examination. Neurology, 62, 534-535. doi: 10.1212/WNL.62.4.534

Cummings, J.L., Doody, R., \& Clark, C. (2007). Disease-modifying therapies for Alzheimer disease: Challenges to early intervention. Neurology, 69, 1622-1634. doi: 10.1212/01.wnl.0000295996.54210.69 
Derenzi, E., \& Vignolo, L.A. (1962). The token test: A sensitive test to detect receptive disturbances in aphasics. Brain, 85, 665-678. doi: 10.1093/brain/85.4.665

Di Giacomo, D., De Federicis, L.S., Pistelli, M., Fiorenzi, D., Sodani, E., Carbone, G., \& Passafiume, D. (2012). The loss of conceptual associations in mild Alzheimer's dementia. Journal of Clinical and Experimental Neuropsychology, 34, 643-653. doi: 10.1080/13803395.2012.667393

Emery, V.O.B. (2000). Language impairment in dementia of the Alzheimer type: A hierarchical decline?. International Journal of Psychiatry in Medicine, 30, 145-164. doi: 10.2190/x09p-n7au-ucha-vw08

Fernández-Blázquez, M.A., Ruíz-Sánchez de León, J.M., López-Pina, J.A., Llanero-Luque, M., Montenegro Peña, M., \& Montejo-Carrasco, P. (2012). A new shortened version of the Boston naming test for those aged over 65: An approach from item response theory. Revista de Neurologia, 55, 399-407. Retrieved from: http://www.revneurol.com/sec/resumen.php?or=pubmed\&id=2012075\#

Fernández-Turrado, T., Pascual-Millán, L.F., Fernández-Arín, E., Larrodé-Pellicer, P., Santos-Lasaos, A.S., \& Mostacero-Miguel, E. (2007). Modelo de análisis en dos mitades para tareas de fluidez semántica [Model of analysis in two halves for semantic fluency tasks]. Revista de Neurologia, 44, 531-536. Retrieved from: http://www.revneurol.com/sec/resumen.php?id=2005690

Folstein, M.F., Folstein, S., \& McHugh, P.R. (1975). Mini-mental state: A practical method for grading cognitive state of patients for clinician. Journal of Psychiatric Research, 12, 189-198. doi: 10.1016/0022-3956(75)90026-6

Fritsch, T., McClendon, M.J., Smyth, K.A., Lerner, A.J., Friedland, R.P., \& Larsen, J.D. (2007). Cognitive functioning in healthy aging: The role of reserve and lifestyle factors early in life. The Gerontologist, 47, 307322. doi: $10.1093 /$ geront/47.3.307

Gomez, R.G., \& White D.A. (2006). Using verbal fluency to detect very mild dementia of the Alzheimer type. Archives of Clinical Neuropsychology, 21, 771-775. doi: 10.1016/j.acn.2006.06.012

Haugrud, N., Crossley, M., \& Vrbancic, M. (2011). Clustering and switching strategies during verbal fluency performance differentiate Alzheimer's disease and healthy aging. Journal of the International Neuropsychological Society, 17, 1153-1157. doi: 10.1017/s1355617711001196

Henry, J.D., \& Crawford, J.R. (2004). A meta-analytic review of verbal fluency performance following focal cortical lesions. Neuropsychology, 18, 284-295. doi: 10.1037/0894-4105.18.2.284

Heun, R., Papassotiropoulos, A., \& Jennsen, F. (1998). The validity of psychometric instruments for detection of dementia in the elderly general population. International Journal of Geriatric Psychiatry, 13, 368-380. doi: 10.1002/(sici)1099-1166(199806)13:6<368::aid-gps775>3.3.co;2-0

Horton, A.M. Jr., \& Reynolds, C.R. (2007). Early detection of risk of onset for dementia of the Alzheimer type and subtle executive dysfunction after TBI using the test of verbal conceptualization and fluency during clinical neuropsychological assessment: Two case studies. Applied Neuropsychology, 14, 224-229. doi: $10.1080 / 09084280701509208$

Juncos-Rabadán, O., Facal, D., Soledad Rodríguez, M., \& Pereiro, A.X. (2010). Lexical knowledge and lexical retrieval in ageing: Insights from a tip-of-the-tongue (TOT) study. Language and Cognitive Processes, 25, 13011304. doi:10.1080/01690961003589484

Juncos-Rabadán, O., \& Pereiro, A.X. (1998). Lenguaje narrativo [Narrative language]. In O. Juncos Rabadán (Ed.), Lenguaje y envejecimiento. Bases para la intervención [Language and aging. Basis for intervention] (pp. 47-72). Barcelona: Masson.

Juncos-Rabadán, O., Pereiro, A.X., Facal, D., \& Rodríguez, N. (2010). Una revisión de la investigación sobre lenguaje en el deterioro cognitivo leve [A review about research in language and mild cognitive impairment]. Revista de Logopedia, Foniatría y Audiología, 30, 73-83. doi: 10.1016/S0214-4603(10)70119-4

Kaplan, E., Goodglass, H., \& Weintraub, S. (2005). Test de Vocabulario de Boston [Boston naming test]. In H. Goodglass, E. Kaplan, \& J. García Albea (Eds.), Evaluación de la afasia y de los trastornos relacionados [Aphasia assessment and related disorders] (pp. A3.1-A3.9). Madrid: Médica Panamericana.

Kemper, S. (1992). Language and aging. In F. Craik \& T.A. Salthouse (Eds.), The handbook of aging and cognition (pp. 373-443). Hillsdale, NJ: Erlbaum.

Kertesz, A. (1994). Neuropsychological evaluation of language. Journal of Clinical Neurophysiology, 11, $205-215$. doi:10.1097/00004691-199403000-00005

Lanting, S., Haugrud, N., \& Crossley, M. (2009). The effect of age and sex on clustering and switching during speeded verbal fluency tasks. Journal of the International Neuropsychological Society, 15, 196-204. doi: $10.1017 / \mathrm{s} 1355617709090237$

Lezak, M.D., Howieson, D.B., Loring, D.W., Hannay, H.J., \& Fisher, J.S. (2004). Neuropsychological Assessment $\left(4^{\text {th }}\right.$ ed.). New York, NY: Oxford University Press.

López Pérez-Díaz, A., Dolores Calero, M., \& Navarro-González, E. (2013). Predicción del deterioro cognitivo en ancianos mediante el análisis del rendimiento en fluidez verbal y en atención sostenida [Prediction of cognitive impairment in the elderly by analysing the performance of verbal fluency and sustained attention]. Revista de Neurologia, 56, 1-7. Retrieved from: http://www.revneurol.com/sec/resumen.php?id=2012281

McDowd, J., Hoffman, L., Rozek, E., Lyons, K.E., Pahwa, R., Burns, J., \& Kemper, S. (2011). Understanding verbal fluency in healthy aging, Alzheimer's disease, and Parkinson's disease. Neuropsychology, 25, 210-225. doi: $10.1037 / \mathrm{a} 0021531$

Millán Calenti, J.C., Lodeiro Fernández, S., \& Crespo López, C. (2006). Trastornos neurol_ogicos [Neurologic disorders]. In J.C. Millán Calenti (Ed.), Principios de Geriatría y Gerontología [Geriatrics and gerontology principles] (pp. 425-476). Madrid: McGraw Hill-Interamericana. 
Monsch, A.U., Bondi, M.W., Butters, N., Salmon, D.P., Katzman, R., \& Thal, L.J. (1992). Comparisons of verbal fluency tasks in the detection of dementia of the Alzheimer type. Archives of Neurology, 49, 1253-1258. Retrieved from: http://archneur.jamanetwork.com/article.aspx?articleid=592080

Moreira, L., Schlottfeldt, C.G., Jardim de Paula, J., Daniel, M.T., Paiva, A., Cazita, V., . . . Malloy-Diniz, L.F. (2011). Normative study of the token test (short version): Preliminary data for a sample of Brazilian seniors. Revista de Psiquiatria Clínica, 38, 97-101. doi: 10.1590/S0101-60832011000300003

Murphy, K.I., Rich, J.B., \& Troyer, A.K. (2006). Verbal fluency patterns in amnestic mild cognitive impairment are characteristic of Alzheimer's type dementia. Journal of the International Neuropsychological Society, 12, 570 574. doi:10.1017/s1355617706060590

Pascual-Millán, L.F., Martínez-Quiñones, J.V., Modrego-Pardo, P., Mostacero-Miguel, E., López del Val, J., \& Morales-Asín, F. (1990). El Set-test en el diagnóstico de la demencia [The set-test for dementia diagnosis]. Neurologia, 5, 82-85.

Perkins, L., Whitworth, A., \& Lesser, R. (1997). Conversation analysis profile for people with cognitive impairment. London: Whurr Publishers.

Pichora-Fuller, K. (2003). Cognitive aging and auditory information processing. International Journal of Audiology, 42 (Suppl. 2), 2526-2532. doi: 10.3109/14992020309074641

Pineda, D.A., Mejía-Mag, S.E., Rosselli, M., Ardila, A., Romero, M.G., \& Pérez, C. (1998). Variabilidad en la prueba de Boston para el diagnóstico de las afasias en adultos laboralmente activos [Variability of the Boston test for the diagnosis of aphasia in active adults in terms of work]. Revista de Neurologia, 26, 962-970. Retrieved from: http://www.revneurol.com/sec/resumen.php?id=98112

Reilly, J., Peelle, J.E., Antonucci, S.M., \& Grossman, M. (2011). Anomia as a marker of distinct semantic memory impairments in Alzheimer's disease and semantic dementia, Neuropsychology, 25, 413-426. doi: $10.1037 / \mathrm{a} 0022738$

Reisberg, B., Ferris, S.H., \& de Leon, M.J. (1988). Global deterioration scale (GDS). Psychopharmacology Bulletin, $24,661-663$

Salthouse, T.A. (1991). Theorical perspectives on cognitive aging. Hillsdale, NJ: Laurence Erlaum Associates.

Saxton, K.W., Ratcliff, G., Munro, C.A., Coffey, E.C., Becker, J. T., Fried, L., \& Kuller, L. (2000). Normative data on the Boston naming test and two equivalent 30-item short forms. The Clinical Neuropsychologist, 14, 526-534. doi: 10.1076/clin.14.4.526.7204

Shadden, B.B. (1997). Discourse behaviors in older adults. Seminars in Speech and Language, 18, 143-157. doi: 10.1055/s-2008-1064069

Snitz, B.E., Unverzagt, F.W., Chang, C.C.H., Vander Bilt, J., Gao, S., Saxton, J., . . Gonguli, M. (2009). Effects of age, gender, education and race on two tests of language ability in community-base older adults. International Psychogeriatrics, 21, 1051-1062. doi: 10.1017/s1041610209990214

Snowdon, D.A. (1997). Aging and Alzheimer's disease: Lessons from the nun study. The Gerontologist, 37, 150156. doi:10.1093/geront/37.2.150

Sontam, V., Christman, S.D., \& Jasper, J.D. (2009). Individual differences in semantic switching flexibility: Effects of handedness. Journal of the International Neuropsychological Society, 15, 1023-1027. doi: $10.1017 / \mathrm{s} 1355617709990440$

Spreen, O. \& Strauss, E. (1998). A compendium of neuropsychological test. Administration, norms and commentary ( $2^{\text {nd }}$ ed.). New York, NY: Oxford University Press.

SPSS Inc. (2007). SPSS Base 16.0 for windows user's guide [computer software]. Chicago, IL: Prentice Hall Press.

Taylor, J.K., \& Burke, D.M. (2002). Asymmetric aging effects on semantic and phonological processes: Naming in the picture-word interference task. Psychology and Aging, 17, 662-676. doi: 10.1037//0882-7974.17.4.662

Tierney, M.C., Black, S.E., Szalai, J.P., Snow, W.G., Fisher, R.H., Nadon, G., \& Chui, H.C. (2001). Recognition memory and verbal fluency differentiate probable Alzheimer disease from subcortical ischemic vascular dementia. Archives of Neurology, 58, 1654-1659. Retrieved from: http://archneur.jamanetwork.com/article.aspx?articleid=780627

Toumbaugh, T.N., \& Hubbley, A.M. (1997). The 60-item Boston naming test: Norms for cognitively intact adults aged 25 to 88 years. Journal of Clinical and Experimental Neuropsychology, 19, 922-932. doi: $10.1080 / 01688639708403773$

Troyer, A.K., Moscovith, M., \& Winocur, G. (1997). Clustering and switching as two components of verbal fluency: Evidence from younger and older healthy adults. Neuropsychology, 11, 138-146. doi: 10.1037//08944105.11.1.138

Uomini, N.T. (2009). The prehistory of handedness: Archaeological data and comparative ethology. Journal of Human Evolution, 57, 411-419. doi: 10.1016/j.jhevol.2009.02.012

Verhaeghen, P. (2003). Aging and vocabulary scores: A metaanalysis. Psychology and Aging, 18, 332-339. doi: 10.1037/0882-7974.18.2.332

Weingartner, H.J., Kawas, C., Rawlings, R., \& Shapiro, M. (1993). Changes in semantic memory in early stage

Alzheimer's disease patients. The Gerontologist, 33, 637-643. doi: 10.1093/geront/33.5.637

Welch, L.W., Doineau, D., Johnson, S., \& King, D. (1996). Educational and gender normative data for the Boston naming test in a group of older adults. Brain \& Language, 53, 260-266. doi: 10.1006/brln.1996.0047

Winblad, B., Palmer, K., Kivipelto, M., Jelic, V., Fratiglioni, L., Wahlund, L.O., . . Petersen, R.C. (2004). Mild cognitive impairment - beyond controversies, towards a consensus: Report of the international working group on mild cognitive impairment. Journal of Internal Medicine, 256, 240-246. doi: 10.1111/j.1365-2796.2004.01380.x 
Zahodne, L.B., Glymour, M.M., Sparks, C., Bontempo, D., Dixon, R.A., MacDonald, S.W.S., \& Manly, J.J. (2011). Education does not slow cognitive decline with aging: 12-year evidence from the Victoria longitudinal study. Journal of the International Neuropsychological Society, 17, 1039-1046. doi: 10.1017/s1355617711001044 